\title{
Repensando la relación entre democracia y representación: algunas propuestas para ampliar el canon democrático
}

\author{
Alejandro Monsiváis Carrillo*
}

\begin{abstract}
Resumen
Repensar el concepto de representación política es indispensable para entender diversos desafíos de la democracia contemporánea. Sin embargo, una revisión de la relevancia democrática de la representación se ve limitada por una noción ampliamente aceptada: que la representación y la democracia constituyen principios opuestos y en conflicto. Mientras que la democracia requiere mayor participación popular, la representación supondría elitismo y distanciamiento político. En este trabajo argumentaré que tal planteamiento es desacertado. Asimismo, haré una revisión de los componentes normativos de la democracia, y discutiré el concepto de representación política. Señalaré que la representación se compone de diversos procesos públicos de autorización, control y justificación que son la clave de las múltiples manifestaciones de la política democrática.
\end{abstract}

\begin{abstract}
Rethinking political representation is necessary to understand many contemporary democratic challenges. However, a widely accepted view states that democracy and representation are two irreconcilable principles, thus hindering the theoretical assessment of political representation's democratic relevance. According to this view, what democracy needs is more popular participation; instead, representation involves elitism and political detachment. In this paper I will argue that such a view is inaccurate. Through the reconstruction of the democratic ideal, and the discussion of the concept of political representation, I intend to show that processes of political authorization, accountability and public justification are both elements of political representation and expression of democratic politics.
\end{abstract}

Palabras clave: representación política, democracia, legitimidad, rendición de cuentas, gobernanza, deliberación.

Key words: political representation, democracy, legitimacy, accountability, governance, deliberation.

* Departamento de Estudios de Administración Pública, El Colegio de la Frontera Norte. 


\section{Introducción}

a relación entre la representación y la democracia es históricamente contingente y teóricamente compleja. En el plano histórico, las democracias surgieron a partir de regímenes de gobierno oligárquicos y aristocráticos que empleaban mecanismos representativos. ${ }^{1}$ En el plano teórico, esta articulación no ha quedado exenta de tensiones. Una de las más conocidas es la que se deriva del elemento de separación, introducido por la representación en el ejercicio del poder soberano del demos (Urbinati, 2006). Si el "pueblo", por así decir, no decide por sí mismo de manera directa, entonces no cabe afirmar que las decisiones adoptadas son auténticamente democráticas. Si la complejidad social impide que el "pueblo" se autogobierne en sentido literal, el resultado sería una segunda mejor alternativa: que se gobierne a través de sus representantes. Pero esto implicaría que la democracia contemporánea es, en su origen y en su forma institucional, normativamente imperfecta.

Un segundo problema es que la conceptualización de la relación entre representación y democracia ha sido objeto o, digamos, "presa" de algunas imprecisiones analíticas. Para muchos, cuando se habla de representación política, se está hablando de representación democrática, ${ }^{2}$ la representación democrática es pensada como algo equiparable a la democracia representativa, y la democracia representativa se traduce en votantes, elecciones, partidos políticos y legislaturas. Si bien no se trata de restarle importancia a las instituciones de la democracia representativa, hay que repensar los elementos que quedan obviados en un trayecto que lleva directamente del concepto de representación política a las preferencias electorales, los partidos y la organización legislativa.

1 El autor desea expresar su reconocimiento a los revisores anónimos de este trabajo, por sus certeras observaciones y sugerencias puntuales, que contribuyeron a mejorar los planteamientos contenidos en el texto.

Desde luego, las trayectorias históricas que dan lugar a la democracia, son diversas (Huntington, 1994; Berg-Schlosser, 2009). Sin embargo, la historia del régimen democrático registra progresos paulatinos en lo relativo a la expansión del electorado y a la universalización del sufragio, progresos que se articularon con instituciones representativas ya en operación (véase Manin, 1997; Przeworski, 2010).

2 Esta equiparación conceptual está presente desde el libro seminal de Hanna Pitkin, The Concept of Representation (1967). Posteriormente, la propia Pitkin (2004) señaló que al analizar el concepto de representación, lo hizo pensando en la representación que se ejerce en las instituciones democráticas. 
El objetivo de este trabajo es argumentar que es posible "ampliar el canon" de la representación democrática. ${ }^{3}$ Por un lado, mostraré que las supuestas tensiones normativas entre representación y democracia no constituyen obstáculos insalvables; por el otro, que el papel de la representación en la democracia tiene que ser repensado desde una revisión de ambos conceptos. El concepto de representación política es necesario no solamente para continuar estudiando la democracia representativa, sino también para entender las consecuencias democráticas de diversas formas de participación y acción públicas.

\section{Representación y democracia: consideraciones preliminares}

Este trabajo se origina en la idea de que las relaciones de representación política son un elemento clave para entender, analizar y problematizar la democracia. Se podría decir que esta aseveración constata un dato trivial: las relaciones entre electores, partidos, gobernantes y legislaturas, son constitutivas de la democracia. Esta consideración, a su vez, tiende a dar por sentado que las cuestiones relativas a la representación democrática están circunscritas a la operación de los partidos y el régimen político, y que, a fin de cuentas, este conjunto de procesos engloban la política democrática. Si las cosas fueran así, la teoría política podría dejar de preocuparse por entender las transformaciones políticas contemporáneas y dedicarse a la exégesis de los textos clásicos.

Sin embargo, hay diversos motivos que invitan a repensar la relación entre la representación y la democracia. En primer lugar, se encuentra el hecho de que las instituciones representativas atraviesan por un momento en el que su credibilidad se encuentra mermada. Por regla general, la opinión pública desconfía de políticos, partidos y parlamentos. Esto no significa que las expectativas democráticas hayan disminuido, pues numerosas formas de acción e intervención públicas consiguen motivar y movilizar con eficacia a los ciudadanos. Pero de cualquier forma, esos problemas de credibilidad y confianza hacen necesaria una nueva reflexión acerca de la relevancia y el futuro de la democracia representativa (Alonso, Keane y Merkel, 2011).

En segundo lugar, es una realidad que los mecanismos representativos del gobierno democrático coexisten actualmente con una amplia variedad de formas de gobernanza colaborativa y participativa. Es innegable que

3 Un estimulante e influyente texto de Santos y Avritzer (2004) merece todo el crédito por la idea de "ampliar el canon democrático" desde la perspectiva de la democracia participativa. 
los movimientos sociales y los instrumentos de participación y democracia directa, se están convirtiendo en mecanismos que sirven como complemento a las instituciones representativas en el cumplimiento de las tareas del gobierno democrático (Peruzotti y Seele, 2009). ${ }^{4}$ Sin embargo, la relación de complementariedad que existe entre las instituciones representativas y los mecanismos de gobernanza participativa, tiende a concebirse como si se pusieran en juego dos modalidades diferentes y separadas de acción política. No siempre se alcanza a ver que los formatos y episodios de acción pública y gestión participativos, contienen elementos propios de las relaciones de representación democrática: procesos de autorización, reivindicaciones públicas, pretensiones de legitimidad y mecanismos de control, entre otros. Los elementos representativos de las modalidades de gobernanza participativa, son una cuestión que debería atraer más poderosamente la atención de los especialistas.

En tercer término se encuentra la necesidad de ir más allá de la aparente tensión irreductible entre el principio democrático y el gobierno representativo (Manin, 1997; Pitkin, 2004; Wolin, 2004). Para muchos, el gobierno representativo puede ser asumido como el precio que hay que pagar por la institucionalización de la soberanía popular. ${ }^{5}$ La escala y diferenciación funcional de las sociedades modernas, por ejemplo, impiden reproducir a escala sistémica un modelo comunitario, directo y participativo de la democracia. Si se quiere legitimidad democrática en los Estados contemporáneos, es ineludible que existan elecciones, partidos y parlamentos. Desde cierto punto de vista, el precio que es necesario pagar por la democracia, es alto, pues su carácter procedimental puede convertirla en un sistema elitista, distante del ciudadano común y con pocos controles efectivos sobre el quehacer de los políticos profesionales. En cambio, los partidarios del gobierno representativo, más afines a la filosofía política liberal, ven las elecciones y los pesos y contrapesos, como un antídoto contra los posibles excesos del "pueblo" en el poder, o simplemente como una forma de dejar asuntos tan importantes como las decisiones políticas en manos de los más aptos. ${ }^{6}$

$4 \quad$ El papel de la representación se está repensando también desde las aportaciones de la participación ciudadana y de las organizaciones de la sociedad civil, en las innovaciones democráticas y la rendición de cuentas. Véase Gurza e Isunza (2010).

5 Los teóricos afines a la democracia participativa, por lo general ven con recelo y escepticismo la posibilidad de que las instituciones representativas sirvan para "empoderar" a los ciudadanos y combatir los privilegios de las élites. Véase Fung y Olin-Wright (2003); Santos y Avritzer (2004); Pateman (1976) y Wolin (2004).

6 El temor a la "tiranía de la mayoría" es heredero de una tradición que ve en la democracia un régimen apto para pequeñas colectividades, en las que es viable utilizar instrumentos directos de participación, pero que es a la vez inestable y dado a la arbitrariedad. Este concepto 
Este trabajo sostiene que para entender mejor el funcionamiento de la gobernanza democrática, es necesario contar con una comprensión de la representación política que haya dejado atrás el supuesto de que existe una tensión de origen, de carácter normativo, entre el gobierno representativo y la soberanía popular. La idea de que existe una contradicción de origen entre la representación y la democracia, puede considerarse válida si se asume que:

1. La democracia es una forma de autogobierno que se conduce con apego a la voluntad general de los ciudadanos.

2. Sólo la participación directa de los ciudadanos produce resultados democráticamente legítimos.

3. Las instituciones representativas convierten a la democracia en un juego competitivo destinado a asegurar la rotación de las élites en el poder.

La presencia de cualquiera de estos tres supuestos, es suficiente para concebir de manera problemática la relación entre representación y democracia. Mostraré más adelante que estos supuestos no constituyen planteamientos definitivos. Esto abre la posibilidad de repensar el papel de la representación en la democracia. Para explorar esa posibilidad, hay que tener en cuenta otras tres cuestiones:

1. La democracia es, antes que un régimen de gobierno, una estructura regulativa para la conducción de la acción pública.

2. La representación democrática es una forma particular de relación, en la que se conjuntan dos elementos: a) relaciones de representación política, y b) criterios democráticos de regulación.

3. Distintas modalidades de autorización, reivindicación, actuación, evaluación y rendición de cuentas público-políticas, pueden ser analizadas como formas de representación democrática.

En lo que sigue, discutiré cada uno de los puntos enunciados. Comenzaré trazando las líneas generales del ideal regulativo de la democracia, y después procederé a revisar los supuestos enlistados arriba, y dedicaré el resto del texto a discutir la relevancia democrática de la representación.

se encuentra en Montesquieu, Tocqueville y Los Federalistas, por mencionar a algunos, y es compartido hasta por Weber, Schumpeter y teóricos de la posguerra. Véase Held (2006), Dahl (1989) y Manin (1997). 


\section{La democracia como ideal regulativo}

La centralidad de la democracia en el pensamiento político contemporáneo, radica en que constituye una estructura básica ideal para dirimir los problemas políticos y conducir la acción colectiva en contextos de desacuerdo y conflicto (Warren, 1996). La democracia es una forma de coordinación política que aspira a la conducción de los asuntos públicos con base en el juicio político de un demos, cuyos integrantes se reconocen como libres e iguales. Este ideal se sostiene sobre las normas de inclusión, equidad y autonomía políticas de los individuos (Dahl, 1971, 1989; Habermas, 1998; Held, 2006, y Warren, 2006). Las normas democráticas posibilitan que las tareas colectivas de identificar intereses comunes y elegir entre alternativas de política, tengan lugar en un marco de inclusión política, contienda deliberativa y rendición de cuentas pública (Chambers, 2003; Dryzek, 2000; Guttman y Thompson, 2004).

El ideal democrático se traduce en un procedimiento para constituir la autoridad, conducir la gobernanza y dar legitimidad a las decisiones colectivas (Habermas, 1998). Podría pensarse que una concepción en que la voluntad colectiva y la legitimidad política quedan despojadas de contenido sustantivo, no proporciona más que una versión instrumental y reduccionista de la democracia. Tal apreciación es infundada. Que sea un método o un procedimiento, no significa que sea un esquema formalista ni un conjunto de prescripciones que se instrumentan mecánicamente. Se trata de un conjunto de normas y prácticas políticas cuyo contenido está orientado a regular los procesos de decisión y acción colectivas, los cuales serán respaldados por una autoridad. De hecho, el "procedimiento democrático" se traduce en los "derechos democráticos" (Munck, 2007) que vinculan a los individuos con el Estado de derecho, el bienestar social y la autonomía política.

Este trazo general describe los parámetros regulativos de los que dependen la constitución de la autoridad, la adopción de decisiones vinculantes y la gobernanza en toda sociedad que aspire a la legitimidad democrática. Cabe hacer notar que de este planteamiento no se desprenden lineamientos por los que cierto tipo de modelos institucionales, o de relaciones políticas directas o indirectas, deban ser considerados intrínsecamente más democráticos que otros. Esta concepción deja abierta la posibilidad de que existan diversos instrumentos y arreglos institucionales que pueden facultar o promover, de una u otra manera, los ideales democráticos. De lo que se trata es de indagar, sin perder de vista una perspectiva normativa, cuáles son las consecuencias políticas de determinados arreglos institucionales. 
Es preciso estudiar de qué manera el federalismo, la descentralización, los distintos sistemas electorales, los instrumentos de democracia directa o las consultas deliberativas - por mencionar sólo algunos casos -, contribuyen a promover la inclusión política, la deliberación, el control público, la legitimidad de las decisiones colectivas y otros componentes del principio democrático.

\section{Revisando las tensiones entre representación y democracia}

Bajo ciertas premisas, las relaciones representativas suelen concebirse como sucedáneos de otras formas de expresión democrática supuestamente más auténticas. Esto sucede si se piensa que la legitimidad democrática sólo proviene de la participación directa e inmediata de cada miembro del "pueblo" en el descubrimiento de una "voluntad general", o cuando se asume que las elecciones y las instituciones representativas son incompatibles con un público activo y deliberativo. En esta sección, mi objetivo es mostrar que tales supuestos son infundados.

Comenzaré señalando que la democracia no puede ser equiparada a un modelo de autogobierno que se conduce con apego a la voluntad general del "pueblo". La democracia surgió, en la época moderna, como un ideal de autogobierno (Przeworski, 2010). El autogobierno implica que la legitimidad de la autoridad política está ligada a la autodeterminación de un pueblo: sólo será libre un pueblo regido por las leyes que por sí mismo ha decidido adoptar. Esta concepción de la democracia produce el siguiente problema: el autogobierno será auténtico si y sólo si los ciudadanos ejercen su soberanía de manera directa, sin mediaciones. Por lo tanto, sólo serán verdaderas democracias aquellos regímenes en los que los miembros de una comunidad política sean a la vez ciudadanos y legisladores. Si por cualquier motivo esto no es posible, lo que queda no son sino sucedáneos. Desde esta óptica, la democracia representativa, por ejemplo, podría ser una alternativa efectiva; pero no dejará de ser una segunda mejor opción.

La teoría del autogobierno tiene diversas dificultades. La primera tiene que ver con el papel que cumple la noción de la voluntad general en la teoría de la democracia. A grandes rasgos, la tesis de Rousseau establece que la soberanía se ejerce cuando los ciudadanos actúan con apego a la voluntad que emana de las voluntades de todos. Esto requiere que cada miembro del colectivo manifieste de manera directa su voluntad política: ésta es algo que no se representa ni se delega. La coherencia de este planteamiento depende, en buena medida, de que la legitimidad política 
radique necesariamente en la existencia de una voluntad general como entidad sustantiva: aquello que es discernible sólo para el colectivo en su conjunto.

La cuestión está en que ni la voluntad general ni el bien común existen como entidades objetivas ni sustantivas. El desarrollo de una teoría de la democracia desligada de la noción del bien común y la voluntad general, tiene en Schumpeter (1970) a un ilustre y acerbo expositor. De la misma manera, la teoría de la elección social ha demostrado que el resultado de las decisiones colectivas depende del procedimiento de agregación de preferencias individuales que se utilice. Bajo ciertos supuestos teóricos, el proceso de agregación de preferencias puede arrojar resultados incoherentes e irracionales (Arrow, 1951). Estos hallazgos han dado fundamento a los recelos que provoca el gobierno popular. Como antídoto, Riker (1982) elogió los pesos y contrapesos del gobierno de la ley, tal como están instaurados en la Constitución estadounidense.

La inestabilidad propia de los procesos de agregación de preferencias individuales, no debe ser juzgada como un defecto constitutivo de la democracia. Si la coherencia de las decisiones colectivas depende de las reglas de agregación de preferencias, entonces adquieren relevancia las condiciones en que se estructuran las alternativas y los procesos de decisión política. Lo que se requiere son normas, instituciones y procesos que hagan valer, de manera clara y eficaz, tanto la igualdad pública de los ciudadanos en los procesos de conformación de la agenda, como la deliberación y las decisiones vinculantes. En el caso que nos ocupa, el ejercicio de la representación contribuye, mediante diversas instancias en los procesos legislativos, a dar forma a la opinión pública, a la configuración de alternativas y a la organización de las decisiones políticas.

Si se deja de lado la expectativa de que la democracia funcione a partir de la manifestación de una supuesta voluntad general, persiste una segunda dificultad: la inmediatez que se exige a la relación entre voluntad individual y voluntad colectiva. En un sistema representativo, las decisiones, leyes y políticas son adoptadas por agentes que actúan en nombre de los representados. Esto, a su vez, significa que la relación política que se establece entre quienes detentan la autoridad en última instancia y las decisiones o acciones del gobierno, es indirecta. Esta relación resulta incómoda para una concepción de la democracia en la que normativamente se espera un vínculo inmediato entre el ciudadano y las decisiones colectivas.

La primera objeción a esta perspectiva se debe a que la escala y complejidad de los sistemas políticos contemporáneos hacen inviable tal modalidad 
de democracia directa. ${ }^{7}$ Es poco realista esperar que millones de personas se involucren directamente en las decisiones políticas y legislativas de un régimen, aunque se tenga la expectativa de que el desarrollo tecnológico ponga remedio a este problema algún día. Inclusive si las tecnologías de la información llegan a comunicar instantáneamente a millones de personas, persiste, no obstante, un problema de carácter funcional. Las decisiones políticas suponen un conocimiento especializado y el dominio de la técnica jurídica; demandan a la vez profesionalización, capacidades de negociación, deliberación e intercambio, y recursos que no están distribuidos de manera uniforme: tiempo, dinero y disposición.

Las limitaciones prácticas y funcionales a la intervención directa de los ciudadanos en las decisiones políticas, son decisivas; pero pueden no ser normativamente convincentes. Mientras que para unos la democracia es posible en las sociedades contemporáneas sólo en la medida en que quede desligada de la noción de una voluntad general sustantiva y adopte la forma de un régimen de derechos e instituciones, para otros, en las condiciones actuales, la democracia sólo puede ser algo que se manifiesta en pequeña escala, descentralizada o excepcional, en momentos de auténtica irrupción popular (Wolin, 2004: 602-603). Es necesario, por lo tanto, llevar un paso adelante la crítica normativa. Antes hay que enfatizar que esto no constituye un argumento en contra de los mecanismos de democracia directa. El punto es otro: no se puede fundamentar una concepción convincente de la democracia únicamente en la norma de la participación directa.

Se trata de insistir en una concepción, digámoslo así, constructivista de la política democrática: la "voluntad" que habrá de gobernar es una "voluntad" que se configura de manera endógena en el proceso político. Las decisiones colectivas son producto de un proceso que supone momentos de deliberación, actuación y evaluación públicas. El carácter democrático viene dado por la posibilidad que tienen los ciudadanos de participar en las distintas fases de tal proceso, de manera directa o indirecta, a través de distintos dispositivos institucionales. La democracia no es una sucesión de actos discretos en los que la comunidad se reúne para adoptar decisiones políticas (Urbinati, 2006:225), ${ }^{8}$ sino un proceso ineludiblemente constituido a lo largo del tiempo, en el que las decisiones colectivas responden, en úl-

7 Dahl (1989), Habermas (1998) y Held (2006), entre otros, han desarrollado con mayor detalle una defensa normativa de la democracia contemporánea, dadas la complejidad y la diferenciación funcional de las sociedades modernas.

8 De acuerdo con Urbinati (2006:225), "en la primera [la democracia directa], la voluntad (will) devora a la política en una serie de actos discretos y absolutos de decisión. En la última [la democracia representativa], la política es una narración ininterrumpida de propuestas y 
tima instancia y a través de mecanismos diversos de intervención política, a los ajustes y cambios en las preferencias de una ciudadanía heterogénea en sus intereses y experiencias políticas.

Una tercera fuente de tensiones entre la teoría de la democracia y el gobierno representativo, proviene del hecho de que la democracia representativa es, en efecto, heredera de una tradición elitista y aristocrática (Manin, 1997; Ferejohn y Rosenbluth, 2009). Antes de la expansión del sufragio universal, las elecciones se instituyeron para seleccionar a una aristocracia electiva, no para dotar de poder a las masas. Es a partir del desarrollo de una concepción realista de la democracia, que se consolida una distribución tajante de funciones y atribuciones políticas: a los líderes y políticos profesionales les corresponde decidir y gobernar; al pueblo, mantenerse al margen de la política y limitarse a acudir a las urnas periódicamente (Schumpeter, 1970). Esta concepción de la democracia ha ejercido una amplia influencia en la teoría política de la posguerra, y ha sido decisiva para dotar a las instituciones representativas de connotaciones opuestas a la participación y el involucramiento populares.

El sesgo elitista o, por lo menos, receloso de una apertura más amplia en las instituciones representativas, se ha visto acentuado por los sesgos prevalecientes en los regímenes políticos actuales. El funcionamiento de las instituciones políticas puede estar lejos de ser óptimo en los casos en que las reglas han respondido a los intereses particulares de élites y grupos concretos. A lo largo de la historia, las instituciones representativas han sido en general moldeadas por actores que han querido promover o resguardar sus privilegios de clase, corporativos, partidistas o simplemente de índole personal. Esto no significa, sin embargo, que las instituciones no se hayan diversificado y transformado, en múltiples casos, para responder a las demandas de inclusión popular del electorado en su conjunto, o de grupos minoritarios o en desventaja.

Las reacciones contra las acepciones y consecuencias elitistas de la democracia, no se han hecho esperar. No es necesario compartir la visión rousseauniana de la soberanía popular, ni la concepción clásica de la democracia como obtención del bien común, para suscribir las numerosas objeciones que se pueden hacer a tal concepción. Aun reconociendo que la gobernanza y la gestión pública son complejas, es insostenible la idea de que el involucramiento de los ciudadanos en la democracia debe limitarse a elegir representantes. Una democracia robusta exige una esfera pública

proyectos que unifica a los ciudadanos y requiere de ellos que se comuniquen en torno a un espacio normativo y a lo largo del tiempo [traducción propia]". 
dinámica y propositiva, integrada por múltiples dinámicas asociativas y esquemas de cogobierno; una esfera pública donde una amplia variedad de actores, redes y organizaciones desempeñen funciones de vigilancia, escrutinio y colaboración.

A diferencia de lo previsto por las concepciones schumpeteriana y minimalista de la democracia, los partidarios de las innovaciones democráticas han mostrado que los modelos de conducción participativa de las políticas han hecho aportaciones a la eficacia de los programas públicos, al desarrollo de capacidades políticas entre sectores de la población habitualmente pasivos o excluidos, al fortalecimiento del Estado de derecho, a la aplicación de la ley y a la rendición de cuentas (Fung, 2006; Smith, 2009). Sin embargo, el giro participativo en la teoría de la democracia tiende a reproducir una inclinación contraria a la representación política. Para ponerlo en términos contrastantes: si durante el siglo XX las concepciones realistas de la democracia desdeñaron el potencial de la participación pública, el surgimiento de las concepciones deliberativas y participativas de la democracia han hecho lo propio con las instituciones representativas. Es preciso rebasar esta oposición, si se pretende tener una mejor comprensión del rol de la representación política en la gobernanza democrática. La premisa es la que ha desarrollado Plotke (1997:30) al defender a la representación como una forma de inclusión que ayuda a constituir capacidades y prácticas democráticas.

En esta sección he defendido la idea de que no existe una tensión de origen entre representación y democracia. Para desarrollar las consecuencias de este planteamiento, hay que revisar, a la vez, el propio concepto de representación.

\section{La representación política}

El concepto de representación es semánticamente denso y evocador: una imagen pictórica puede representar un objeto del mundo; un actor representa a un personaje; un abogado actúa con conocimiento de las leyes y la técnica legal para promover los intereses de su cliente en las instancias apropiadas. Los monarcas, a diferencia de Luis XIV, representan al Estado, como lo hacen también los presidentes en las democracias constitucionales.

De acuerdo con Hanna Pitkin, la representación política significa "actuar en el interés de los representados, de una manera responsable hacia ellos" (Pitkin, 1967: 209). La definición de Pitkin puede ser traducida a los términos de una relación principal-agente. El principal es la entidad que autoriza 
y delega el poder en un agente. Esto se hace bajo algún tipo de arreglo en el que se define lo que el principal espera que haga el agente, y también las consecuencias se pueden derivar del hecho de que el agente no cumpla con lo previsto. Esta fórmula es analíticamente útil para teorizar las relaciones de representación que tienen lugar en los regímenes democráticos (Ferejohn, 1999; Manin, Przeworski y Stokes, 1999). En una democracia, el electorado constituye el principal, y los legisladores, o el titular del Ejecutivo, el agente. El mecanismo de autorización son las elecciones libres, que determinan qué condiciones deben cumplirse para que los votos se conviertan en puestos de representación popular. Los representantes electos asumen su responsabilidad ante el electorado y se comprometen a actuar de manera consecuente con esa responsabilidad. Un nuevo periodo electoral es el momento en que los votantes deciden si reeligen a sus gobernantes o los cambian por otros.

Si se le ve de esta manera, la representación política conduce a problemáticas teóricas con connotaciones normativas y analíticas de distinta índole. Una serie de cuestiones se anudan en torno a una interrogante fundamental: ¿cómo debe constituirse y ejercerse la representación? ¿Deben los órganos representativos ser reflejo fiel y proporcional de la comunidad política? ¿Solamente los miembros de un mismo grupo, o los individuos que comparten una misma condición, pueden ser representantes de esos grupos o individuos? Estas preguntas se cruzan con otras cuestiones, igualmente relevantes: ¿deben los representantes actuar con apego a un mandato, o son libres de actuar conforme a su propio juicio? ¿Cómo se hace rendir cuentas a los representantes? ¿Qué tan legítimo es que los políticos hagan lo contrario a lo que prometieron al llegar al gobierno (Stokes, 2001)?

Este conjunto de interrogantes atañe directamente a la relación entre representación, rendición de cuentas y desempeño democrático. Por una parte, el modelo principal-agente es un componente de una concepción económica de la democracia. Para esta visión, las elecciones constituyen un sistema que opera bajo las reglas de un mercado político: de un lado existen políticos que ofertan sus propuestas; del otro, electores que habrán de elegir la alternativa más cercana a sus preferencias. Como todo mercado, las elecciones son susceptibles de distorsiones diversas: costos de entrada, información incompleta, monopolios políticos, entre otras. Esto dificulta que las elecciones sean, en la práctica, un instrumento capaz de garantizar que los políticos actuarán responsablemente, de acuerdo con Pitkin (1967), en interés de sus representados. Esas dificultades están inscritas en la misma estructura de la relación principal-agente: los agentes se benefician de la asimetría de información a la que acceden, y el electorado dispone de 
instrumentos imperfectos para controlar efectivamente a sus representantes y a los gobiernos (Manin, Przeworski y Stokes, 1999; Maravall, 2006).

Sin embargo, nótese que el modelo principal-agente conduce, sin mucha discusión, a entender la representación democrática a través de las relaciones de autorización electoral. De manera semejante, el debate normativo sobre la representación da por sentado que los parámetros de evaluación son los principios democráticos. En estos casos, como puede ser en otros, se asume que la representación política es un fenómeno que, salvo aclaración de por medio, adopta la forma de la representación democrática. Diversas agendas de investigación pueden proceder sobre la base de este conjunto de supuestos, en aras de economizar aclaraciones y discusiones teóricas (Powell, 2004; Wessels, 2009). Esto no implica, sin embargo, que las controversias conceptuales y normativas de fondo hayan sido resueltas.

Para repensar la relación entre democracia y representación, es necesario distinguir ambos conceptos; es decir: desligar los parámetros normativos de la democracia de la conceptualización de la representación política. La representación política es un tipo de relación que se establece y opera en contextos y bajo reglas que no requieren ser las de la democracia. Las condiciones necesarias y suficientes que definen la representación política han sido analizadas en detalle por Rehfeld (2006). Exponiéndolo de manera sumaria, se tiene representación cuando existe una función que requiere un representante; un postulante es elegido de entre el conjunto de postulantes cualificados para cumplir con esa función; la elección del postulante se da conforme a la regla reconocida como válida; hay un agente facultado para aplicar la regla de elección; el postulante acepta el cargo, y la audiencia relevante certifica que se cumplieron las condiciones descritas (Rehfeld, 2006:6). Esta serie de condiciones necesarias y suficientes puede aplicarse a diversas relaciones representativas: desde las que establecen electores y legisladores, hasta las que emplean autócratas y sus delegados en organizaciones internacionales.

Sobre esta base, es necesario hacer dos consideraciones que podrían parecer obvias. La primera es que el estudio del funcionamiento de la representación política puede hacerse sin tener como horizonte normativo a la democracia. La segunda es que los parámetros normativos de la democracia pueden utilizarse para analizar los atributos y el desempeño de los sistemas electorales, los partidos políticos, la organización legislativa, las relaciones entre poderes y otras instituciones representativas; pero también pueden emplearse para estudiar y evaluar otras dinámicas representativas. El desafío está en identificar formas de representación democrática que operan de manera paralela y complementaria a las instituciones de la democracia 
representativa. Por ejemplo, Urbinati y Warren (2008:405) han señalado que lo que caracteriza a las expresiones de una democracia participativa y de compromiso cívico, no es tanto un involucramiento ciudadano generalizado, sino el potencial que tienen estas expresiones para representar perspectivas, discursos, identidades e intereses. Para estos autores, existen numerosas formas de representación democrática no-electoral, que asumen la forma de agentes autorizados por sí mismos, o de múltiples espacios de "representación ciudadana". Estas manifestaciones representativas quedan expresadas en las reivindicaciones de organizaciones internacionales, grupos de interés, asociaciones filantrópicas, actividades periodísticas, consejos consultivos, audiencias públicas, foros deliberativos, paneles de especialistas, protestas colectivas y demás.

El mosaico de formas representativas emergentes es tan variado como dinámico. Es por ello que la teoría de la democracia debe interesarse en el funcionamiento y las consecuencias de dinámicas representativas noelectorales, tanto como lo hace por la operación de las instituciones de la democracia representativa.

\section{La representación democrática}

El concepto de representación política está ligado al estudio de las relaciones entre votantes, candidatos, partidos, elecciones, reglas electorales, legislaturas y desempeño legislativo (Powell, 2004). Todos estos elementos son componentes esenciales de la política democrática, como lo son también las dinámicas asociativas, las innovaciones participativas en la gobernanza y la deliberación en la esfera pública. Una comprensión adecuada del funcionamiento y de los desafíos de la democracia contemporánea, requiere conjuntar estas dos vertientes de la teorización política: la que pone énfasis en las instituciones representativas y la que se interesa por las manifestaciones participativas y deliberativas.

Las dinámicas de representación política no acontecen solamente en el registro delimitado por las instituciones de la democracia representativa: el "lienzo" de la representación es mucho más amplio (Saward, 2011). Las dinámicas representativas están presentes asimismo en las modalidades de acción pública que se manifiestan en la sociedad civil y en la conducción de las políticas públicas. Es pertinente, por tanto, analizar sus características, sus consecuencias y su relevancia democrática. Siguiendo la formulación de Urbinati y Warren (2008), se puede decir que existen tres elementos generales que deben ser objeto de escrutinio: 
1. Las modalidades de autorización.

2. Los contenidos de la representación.

3. Las modalidades de control y rendición de cuentas.

Para dar cuenta de las modalidades de autorización, se puede seguir la ruta definida por el estudio de las instituciones electorales: es necesario definir quién puede votar, quién puede ser electo, bajo qué condiciones y con qué procedimientos. Cuando se trata de enfocar las formas no-electorales de representación, hay que tener mayor cuidado en delimitar las condiciones de autorización: ¿en qué escenarios, coyunturas o situaciones existen individuos o grupos que dicen representar ideas, intereses o personas? Las mismas consideraciones son pertinentes cuando se examinan los contenidos de la representación. Un legislador, por el simple hecho de haber obtenido un escaño bajo un procedimiento determinado, y de estar sujeto a la influencia que sobre su comportamiento pueda tener un partido político, puede representar a su distrito, a su región o al país entero en los procesos legislativos en los que se habrá de involucrar. En las modalidades no electorales de representación, hay que especificar con igual detalle cuáles son los programas de política, las iniciativas o las demandas que son defendidas o promovidas por los representantes. Para evaluar las modalidades de control, es necesario saber cómo se evalúa la calidad de la representación, qué sanciones o acciones son posibles y qué instrumentos están disponibles para que haya rendición de cuentas. Estos elementos son endógenos a las relaciones representativas, pues están determinados por los contextos en los que tiene lugar la representación política.

La representación democrática se construye por medio de la operación de diversos mecanismos de autorización, actuación y control, lo que permite a agentes concretos abogar por los intereses de aquellos a quienes representan. La pregunta que se genera es cómo evaluar desde la teoría de la democracia a las distintas manifestaciones de representación política. Ésta es una cuestión controvertida. Cerraré este trabajo revisando tres cuestiones centrales en el análisis de la representación democrática: la construcción discursiva de la representación, los modelos de representación democrática, y la rendición de cuentas pública en la representación política.

\section{El juicio político y las reivindicaciones representativas}

La democracia es una forma de gobierno que requiere de procesos de deliberación y justificación de las decisiones colectivas. Las decisiones demo- 
cráticas eligen entre alternativas en una agenda que ha sido configurada a partir de planteamientos públicos de distinta índole. Dan forma jurídica y política a opiniones formadas sobre consideraciones normativas, técnicas y estratégicas. Como ha sugerido Warren (2006), a esto es a lo que se puede denominar el "juicio político colectivo": a los planteamientos y justificaciones en torno a los intereses comunes que deben ser alcanzados y promovidos a través de la acción respaldada por el Estado. El juicio político colectivo no es unitario ni definitivo, sino que alude a las contiendas discursivas que moldean la gobernanza democrática.

En la formación colectiva del juicio político desempeña una función central el proceso de construir relatos, discursos y postulados que articulan intereses, perspectivas y preferencias. En tal caso, la representación, en cuanto actividad política, implica recurrir a herramientas discursivas, retóricas, e inclusive de actuación o representación teatral (Saward, 2010). En la representación política tienen tanta centralidad las pretensiones o reivindicaciones representativas (representative claims) como las normas y condiciones de autorización de representantes (Saward, 2010).

Las reivindicaciones representativas pueden ser enunciadas por candidatos, líderes partidistas, líderes de opinión o, en general, por actores sociales. Pueden ser enunciadas en foros particulares, alcanzar amplia difusión en la esfera pública e informar los debates legislativos; pero también pueden agotarse y extinguirse desde el momento de su enunciación. Son las condiciones de producción, circulación y aceptación las que varían de caso en caso. Dado que sus efectos son contingentes, para identificar la aceptación y legitimidad que alcanzan las pretensiones representativas, es necesario reconstruir procesos políticos empíricos. Una reivindicación representativa puede tener eco en una audiencia distinta a la que iba dirigida; y puede contribuir a representar identidades, perspectivas o intereses de una manera más efectiva. Sus consecuencias democráticas, por ende, también dependen de los contextos y situaciones.

Las reivindicaciones representativas y el juicio político colectivo se construyen en múltiples foros y espacios públicos. El lugar concebido normativamente para la deliberación y la justificación pública, es el pleno del parlamento nacional, donde los legisladores debaten unos con otros e, idealmente, configuran mayorías en torno a las leyes que mejor representan los intereses del público. Estos procesos pueden acontecer también en otros espacios políticos. Por ejemplo, las legislaturas locales de las entidades federativas constituyen espacios para la formulación y deliberación de políticas con un alcance claramente delimitado en términos funcionales y jurisdiccionales. Por otra parte, el proceso de formación discursiva de un 
juicio o una consideración público-política, no tiene que culminar en una ley o en una política pública para ameritar interés normativo y analítico. Por ende, diversos foros públicos, esferas participativas, dinámicas asociativas, experimentos deliberativos e instrumentos de gobernanza, constituyen espacios de representación cuando hay redes, organizaciones e individuos que reivindican visiones, intereses y discursos público-políticos.

\section{Modelos de representación democrática}

Las dinámicas representativas están presentes en la formación de la opinión y en los programas y las alternativas de la acción pública. Pero esto constituye sólo una parte de la historia. La representación democrática debe evaluarse por la manera en que las instituciones configuran modelos concretos de coordinación y acción democráticas. La organización institucional del gobierno constitucional puede interpretarse como un marco en el que la soberanía popular se construye a partir de las disputas entre los poderes estatales por la representación democrática (Garsten, 2009). El análisis comparado de las instituciones políticas no sólo revela que las instituciones importan, como afirman los enfoques institucionalistas en general; también muestra que los arreglos institucionales encarnan determinadas visiones de la representación democrática (Lijphart, 2000).

La investigación empírica revela que la gobernanza democrática está constituida por una serie de tensiones estructurales: es difícil obtener efectividad en la toma de decisiones si al mismo tiempo se desea inclusión y representatividad; las dinámicas políticas pueden ser de corte colaborativo o conflictivo, pero no del mismo tipo simultáneamente; los representantes pueden verse inducidos a promover intereses generales, o a favorecer intereses reducidos y particulares.

La investigación en torno al funcionamiento y las consecuencias de las instituciones representativas, enseña que la gobernanza democrática está estrechamente vinculada a los atributos de dos tipos de instituciones: los mecanismos de autorización democrática, y las reglas y prácticas que estructuran el proceso de formulación de políticas. Los sistemas electorales corresponden al primer tipo; la organización de los poderes estatales, al segundo. Los sistemas electorales se componen de las reglas de transformación de votos en escaños, y comprenden el número y el tamaño de los distritos electorales, y el tamaño de la legislatura (Gallagher y Mitchell, 2005). Los sistemas electorales influyen en el número y organización de los partidos políticos, y en el desempeño de los legisladores. Dependiendo del 
sistema electoral, los representantes pueden dar prioridad a asuntos generales y nacionales, y manifestarse más o menos dispuestos a conducirse con disciplina partidista en las votaciones legislativas (Cox y McCubbins, 2001).

La organización de los poderes estatales determina la manera en que se relacionan los poderes Ejecutivo y Legislativo, el carácter más o menos inclusivo del sistema, la eficacia gubernamental, la estabilidad de la democracia y, en general, la calidad de las políticas públicas. En lo relativo a estas cuestiones, la literatura especializada es extensa, comenzando por la discusión originada en torno a los regímenes presidenciales y parlamentarios (Cheibub, 2007). Esta discusión dio lugar a otros debates, como los referentes a los siguientes asuntos: la evaluación del desempeño de las formas proporcionales o mayoritarias de diseño constitucional (Powell, 2000); el carácter mayoritario o de consocios de las instituciones democráticas (Lijphart, 2000); las dinámicas de la concepción neomadisoniana de las instituciones electorales (Carroll y Shugart, 2007); las ventajas del modelo centrípeto de la gobernanza democrática (Gerring y Thacker, 2008), y los mecanismos que, "parlamentarizando" a los sistemas presidenciales, permiten representar mejor las preferencias del votante mediano (Colomer y Negretto, 2005).

Estos trabajos combinan la generación de hallazgos empíricos sistemáticos con la reflexión normativa en torno al funcionamiento de la representación. Si bien la investigación especializada se ha concentrado en las instituciones del régimen democrático, puede no ser desacertado pensar que muchos de sus hallazgos sean extendibles a otros contextos y espacios supranacionales y subnacionales de acción pública.

\section{El control popular y la rendición de cuentas}

Los mecanismos de autorización democrática implican la generación, en paralelo, de mecanismos de control y rendición de cuentas (accountability) (Bovens, 2010). La pregunta central en este contexto, es: ¿cómo pueden asegurarse quienes delegan poder o conceden autoridad, que sus intereses serán promovidos y que no serán, por el contrario, objeto de abusos y arbitrariedades? ¿Cómo obligar a los representantes democráticos a promover los intereses públicos? ¿Cómo evaluar sus acciones? ¿Con qué parámetros?

Sin duda, el tema de la rendición de cuentas es clave en la relación entre representación y democracia. Manin, Przeworski y Stokes (1999) han mostrado que las elecciones son un instrumento limitado para asegurar que los representantes actúen en beneficio de sus representados. Las elecciones 
constituyen sistemas de incentivos y sanciones, pero son insuficientes para asegurar un comportamiento responsable y representativo.

En el plano de la teoría normativa, Mansbridge $(2003,2009)$ ha discutido diversos modelos de representación en los que el comportamiento de los legisladores no está ligado de manera directa al mandato de los electores ni a las posibilidades de recompensa vinculadas a la reelección. Mansbridge (2003) habla de representación subrogada y de representación giroscópica, para capturar facetas de la representación política que escapan a los modelos que oponen a delegados y fiduciarios (trustees), y al dilema entre seguir un mandato $\mathrm{u}$ orientarse por las sanciones electorales. La representación subrogada significa que los legisladores promueven iniciativas que representan los intereses de votantes localizados más allá del distrito en el que fueron electos, mientras que la representación giroscópica no responde a incentivos externos y tiene como motivación última los juicos y las consideraciones internas que los legisladores tienen sobre lo que deben representar. A partir de este modelo giroscópico, Mansdbridge (2009) ha desarrollado el modelo de "selección", caracterizado por representantes que coinciden con las preferencias de sus electores y están motivados internamente por el deseo de promover el interés público; que están dispuestos a proporcionar justificaciones públicas por su comportamiento y se encuentran poco intimidados por las sanciones electorales.

Sea en un contexto electoral o en uno no electoral, la rendición de cuentas en el ejercicio de una función representativa es un tema controvertido. Los representantes pueden ser juzgados por su desempeño y sancionados. Paradójicamente, es difícil saber cómo sancionar a alguien que obedece, digamos, un mandato o cumple un compromiso concreto, cuando las circunstancias exigen hacer otra cosa. Desde el punto de vista de la teoría democrática, con independencia del tipo o la eficacia de las sanciones que puedan imponerse a un representante público, a un legislador, a un segmento de la legislatura o a un gobierno en particular, la tensión fundamental se produce entre la conducta responsable, es decir, la que responde a los intereses de los representados, y el comportamiento orientado prioritariamente por el propio juicio del representante.

Un representante democrático debe actuar de manera responsable, en el sentido de conducir sus acciones y decisiones con base en las preferencias y los intereses del público. En la práctica, puede acontecer que el público tenga intereses contradictorios y preferencias inestables; o también puede presentarse el caso de que la audiencia a la que se representa actúe de manera discriminatoria o en contra de algún tipo de derecho fundamental. Un representante que siga el vaivén de la opinión pública, puede ver 
desestimada su capacidad de actuar como representante. Simétricamente, una persona que se muestra impermeable ante el debate público y la crítica, puede desempeñarse como un político eficaz y determinado, pero no necesariamente como un representante sensible a las demandas populares; éste es el caso del estilo de representación concebido por Edmund Burke.

La complejidad inherente al proceso de rendición de cuentas de los representantes, nos hace ver la importancia de la transparencia y de otras disposiciones e instrumentos de control institucional, y la conveniencia del intercambio de justificaciones públicas que operan en los contextos donde se ejerce alguna función representativa. Así como es clave la disposición de los representantes para conducirse, en el ejercicio de su cargo, con arreglo a un estricto código de ética pública, así también debe considerarse que la calidad de la representación viene ligada a los procesos de deliberación y justificación pública en los que participan representantes y representados.

\section{Conclusiones}

Firmemente arraigado en el imaginario democrático contemporáneo, se encuentra el ideal de una ciudadanía activa y participativa, que se involucre en los asuntos públicos y colabore en la conducción del gobierno. Esta noción está presente en las controversias normativas de los teóricos de la democracia, y hace que veamos con suspicacia la operación de los mecanismos políticos e institucionales que dan forma al gobierno representativo. Y no faltan razones para justificar esta actitud: además de que la historia de las instituciones representativas tiene antecedentes elitistas, hoy en día partidos, legislaturas y líderes políticos, son habitualmente cuestionados por su falta de responsabilidad y por su distanciamiento del público.

El argumento que he desarrollado en este trabajo, apunta en otra dirección, más acorde con la afirmación de Saward (2010:167) de que "toda política democrática es política representativa". En esta línea, he mostrado que la idea de que la democracia y la representación son casi antitéticas se basa en consideraciones insuficientemente fundamentadas. La representación, al igual que la participación política, es un fenómeno político que puede cumplir con estándares democráticos o no, de acuerdo con las condiciones y circunstancias en las que se manifieste. Al mismo tiempo, he señalado que en las relaciones de representación están implícitas reivindicaciones públicas y condiciones de autorización, control y rendición de cuentas, que son elementos constitutivos de la política democrática. 
Este trabajo pretende contribuir a una agenda emergente de investigación en torno a las diversas manifestaciones de representación públicopolítica y a su relevancia democrática. Al mismo tiempo que se mantiene un vivo debate en torno a las instituciones de la democracia representativa, diversas expresiones asociativas, reivindicaciones simbólicas e intervenciones políticas, ponen de manifiesto que existen intereses, identidades y perspectivas que son representadas de varias formas en la esfera pública, y que ameritan una mayor reflexión normativa y una investigación empírica más extensa.

\section{Bibliografía}

Alonso, Sonia, John Keane y Wolfgang Merkel, 2011, “Editor's Introduction: Rethinking the Future of Representative Democracy", en Sonia Alonso, John Keane y Wolfgang Merkel, The Future of Representative Democracy, Cambridge, Cambridge University Press, pp. 1-22.

Arrow, Kenneth, 1951, Social Choice and Individual Values, New Heaven, Yale University Press.

Berg-Schlosser, Dirk, 2009, "Long Waves and Conjunctures of Democratization", en Haerpfer, Christian W., Patrick Bernhagen, Ronald F. Inglehart y Christian Welzel (eds.), Democratizations, Oxford, Oxford University Press, pp 41-54.

Bohman, James, 2010, Democracy across Borders: From Demos to Demoi, Cambridge, The Massachusetts Institute of Technology Press.

Bovens, Mark, 2010, “Two Concepts of Accountability: Accountability as a Virtue and as a Mechanism", West European Politics, vol. 33, núm. 5, pp. 946-967.

Carroll, Royce y Matthew Soberg Shugart, 2007, "Neo-Madisonian Theory and Latin American Institutons", en Gerardo L. Munck (ed.), Regimes and Democracy in Latin America: Theories and Methods, Oxford, Oxford University Press, pp. 51-101.

Chambers, Simone, 2003, "Deliberative Democratic Theory", Annual Review of Political Science, vol. 5, pp. 307-326.

Cheibub, José Antonio, 2007, Presidentialism, Parliamentarism, and Democracy, Cambridge, Cambridge University Press. 
Colomer, Josep y Gabriel Negretto, 2005, “Can Presidentialism Work Like Parliamentarism?", Government \& Opposition, pp. 60-89.

Cox, Gary y Mathew D. McCubbins, 2001, “The Institutional Determinants of Economic Policy Outcomes", en Stephan Haggard y Mathew D. McCubbins (eds.), Presidents, Parliaments, and Policy, Cambridge, Cambridge University Press, pp. 21-63

Dahl, Robert, 1971, Poliarchy: Participation and Opposition, New Heaven, Yale University Press.

Dahl, Robert, 1989, Democracy and Its Critics, New Heaven, Yale University Press.

Dryzek, John, 2000, Deliberative Democracy and Beyond: Liberals, Critics, Contestations, Oxford, Oxford University Press.

Ferejohn, John, 1999, “Accountability and Authority: Towards a Theory of Political 66 Accountability", en Adam Przeworski, Susan Stokes y Bernard Manin (eds.), Democracy, Accountability and Representation, Cambridge, Cambridge University Press, pp. 131-153.

Ferejohn, John y Frances Rosenbluth, 2009, “Electoral Representation and the Aristocratic Thesis", en Ian Shapiro, Susan C. Stokes, Elisabeth Jean Wood y Alexander S. Kirshner, (eds.), Political Representation, Cambridge, Cambridge University Press, pp. 271-304.

Fung, Archon, 2006, "Varieties of Participation in Complex Governance", Public Administration Review, vol. 66, pp. 66-75

Fung, Archon y Erik Olin-Wright, 2003, Deepening Democracy: Institutional Innovations in Empowered Participatory Governance, Londres, Verso.

Gallagher, Michael y Paul Mitchell (eds.), 2005, The Politics of Electoral Systems, Oxford, Oxford University Press.

Garsten, Bryan, 2009, "Representative Government and Popular Sovereignty", en Ian Shapiro, Susan C. Stokes, Elisabeth Jean Wood y Alexander S. Kirshner (eds.), Political Representation, Cambridge, Cambridge University Press, pp. 90-110.

Gerring, John y Strom Thacker, 2008, A Centripetal Theory of Democratic Governance, Cambridge, Cambridge University Press. 
Gurza Lavalle, Adrián y Ernesto Isunza Vera, 2010, "Precisiones conceptuales para el debate contemporáneo sobre la innovación democrática", en Ernesto Isunza Vera y Adrián Gurza Lavalle (coords.), La innovación democrática en América Latina. Tramas y nudos de la representación, la participación y el control social, México, CIESAS-Universidad Veracruzana, pp. 19-82.

Gutmann, Amy y Dennis Thompson, 2004, Why Deliberative Democracy?, Princeton, Princeton University Press.

Habermas, Jürgen, 1998, Facticidad y validez, Madrid, Trotta.

Held, David, 2006, Models of Democracy, 3a. edición, Stanford, Stanford University Press.

Huntington, Samuel P., 1994, La Tercera Ola: democratizaciones a finales del siglo XX, México, Paidós.

Lijphart, Arend, 2000, Modelos de democracia, Barcelona, Ariel.

Manin Bernard, 1997, The Principles of Representative Government, Cambridge, Cambridge University Press.

Manin, Bernard, Adam Przeworski y Susan Stokes, 1999, “Elections and Representation", en Adam Przeworski, Susan Stokes y Bernard Manin (eds.), Democracy, Accountability and Representation, Cambridge, Cambridge University Press, pp. 29-55.

Mansbridge, Jane, 2003, "Rethinking Representation", American Political Science Review, vol. 97, núm. 4, pp. 515-528.

Mansbridge, Jane, 2009, “A «Selection Model» of Political Representation”, Journal of Political Philosophy, vol. 17, núm. 4, pp. 369-398.

Maravall, José María, 2006, "Accountability and the Survival of Governments", en Charles Boix y Susan Stokes, The Oxford Handbook of Comparative Politics, Oxford, Oxford University Press, pp. 910-939.

Munck, Gerardo, 2007, “The Study of Politics and Democracy: Touchstones of a Research Agenda", en Gerardo L. Munck (ed.), Regimes and Democracy in Latin America: Theories and Methods, Oxford, Oxford University Press, pp. 25-38.

Pateman, Carol, 1976, Participation and Democratic Theory, Cambridge, Cambridge University Press. 
Peruzzotti, Enrique y Andrew Seele, 2009, "Participatory Innovation and Representative Democracy in Latin America", en Andrew Seele y Enrique Peruzzotti (eds.), Participatory Innovation and Representative Democracy in Latin America, Washington, D.C., y Baltimore, Woodrow Wilson Center Press, The Johns Hopkins University Press, pp. 1-16.

Pitkin, Hanna F., 1967, The Concept of Representation, Berkeley, University of California Press

Pitkin, Hanna F., 2004, "Representation and Democracy: Uneasy Alliance", Scandinavian Political Studies, vol. 27, núm. 3, pp. 335-342.

Plotke, David, 1997, "Representation is democracy", Constellations, 4, pp.19-34

Powell Jr., G. Bingham, 2000, Elections as Instruments of Democracy: Mayoritarian and Proportional Visions, Yale University Press.

Powell Jr., G. Bingham, 2004, "Political Representation in Comparative Politics", Annual Review of Political Science, 7, pp. 273-96

Przeworski, Adam, 2010, Democracy \& the Limits of Self-Government, Cambridge, Cambridge University Press.

Rehfeld, Andrew, 2006, "Towards a General Theory of Political Representation", The Journal of Politics, vol. 68, núm. 1, pp. 1-21.

Riker, William, 1982, Liberalism Against Populism, San Francisco, W. H. Freeman.

Rousseau, Jean-Jacques, 2003, El contrato social, Buenos Aires, Losada, p. 12.

Santos, Boaventura de Souza y Leonardo Avritzer, 2004, "Introducción: para ampliar el canon democrático", en Boaventura de Souza Santos (ed.), Democratizar la democracia: Los caminos de la democracia participativa, México, Fondo de Cultura Económica, pp. 35-74.

Saward, Michael, 2010, The Representative Claim, Oxford, Oxford University Press.

Saward, Michael, 2011, "The Wider Canvas: Representation and Democracy in State and Society", en Sonia Alonso, John Keane y Wolfgang Merkel, The Future of Representative Democracy, Cambridge, Cambridge University Press, pp. 74-96.

Schumpeter, Joseph, 1970, Capitalism, Socialism and Democracy, 3a. edición, Nueva York, Harper Perennial. 
Smith, Graham, 2009, Democratic Innovations: Designing Institutions for Citizen Participation, Cambridge, Cambridge University Press.

Stokes, Susan, 2001, Mandates and Democracy: Neoliberalism by Surprise in Latin America, Cambridge, Cambridge University Press.

Urbinati, Nadia, 2006, Representative Democracy: Principles and Genealogy, Chicago, University of Chicago Press.

Urbinati, Nadia y Mark Warren, 2008, “The Concept of Representation in Contemporary Democratic Theory", Annual Review of Political Science, vol. 11, pp. 387412.

Warren, Mark, 1996, "What Should We Expect from More Democracy? Radically Democratic Responses to Politics", Political Theory, 24 (2), pp. 241-270.

Warren, Mark, 2006, "Democracy and the State", en John Dryzek, Bonnie Honig y Anne Phillips (eds), The Oxford Handbook of Political Theory, Oxford, Oxford University Press, pp. 382-399.

Wessels, Bernhard, 2009, "Political Representation and Democracy", en Russell J. Dalton y Hans-Dieter Klingemann, The Oxford Handbook of Political Behaviour, Oxford, Oxford University Press, pp. 833-849.

Wolin, Sheldon W., 2004, Politics and Vision: Continuity and Innovation in Western Political Thought, Princenton y Oxford, Princeton University Press.

Recibido el 23 de enero de 2012 Aceptado el 14 de septiembre de 2012 
